\title{
SENSITIVITY OF THE CYCLIC RESPONSE OF SUBSTANDARD BEAM-COLUMN JOINTS TO MATERIAL PROPERTIES
}

\author{
Özgür Yurdakul ${ }^{1}$, Ciro Del Vecchio ${ }^{2}$, Marco Di Ludovico ${ }^{2}$ \\ Ladislav Routil ${ }^{1}$, and Özgür Avşar ${ }^{3}$ \\ ${ }^{1}$ Department of Transport Structures, Transport Faculty, University of Pardubice \\ Pardubice, Czech Republic \\ e-mail: ozgur.yurdakul@ student.upce.cz; ladislav.routil@upce.cz \\ ${ }^{2}$ Department of Structures for Engineering and Architecture, University of Napoli Federico II \\ Napoli, Italy \\ \{ciro.delvecchio, diludovi\}@ unina.it \\ ${ }^{3}$ Department of Civil Engineering, Engineering Faculty, Eskişehir Technical University \\ Eskişehir, Turkey \\ ozguravsar@eskisehir.edu.tr
}

\begin{abstract}
The uncertainties related to the material properties may significantly affect the seismic performance of structural components. In this study, the influence of each material property on the global response of reinforced concrete substandard beam-column joints is evaluated by means of a sensitivity analysis. An experimentally validated finite element model (FEM) is used for probabilistic numerical simulations. The material properties defined as random variables are generated by Latin Hypercube Sampling (LHS). The existing correlation among the material parameters is also considered by the simulated annealing approach in generating the random samples. A set of load-displacement curves is obtained by the numerical simulations with the randomized material parameters. The investigated outcomes (i.e., response variables) are the joint shear strength at the first cracking, the joint peak strength, and joint strength and crack width at serviceability limit state, which is considered as a repairability threshold value. The basic statistics of the response variables together with the probability distribution functions $(P D F)$ are calculated at different drift levels. The partial correlation coefficient between material parameters and response variables is also evaluated to outline the parameters which mainly contribute to the joint global response. The reparability level of the joint is also identified stochastically by the crack width distribution corresponding to the serviceability limit state.
\end{abstract}

Keywords: Sensitivity, numerical model, substandard, stochastic assessment, uncertainty 


\section{INTRODUCTION}

Existing reinforced concrete buildings designed and constructed with details non-conforming to current seismic codes are vulnerable to seismic actions. Structural deficiencies mainly arising from the use of low strength concrete, lack of transverse reinforcement in the joint panel and improper anchor length/detail may result in devastating brittle failure of the substandard joints even under moderate seismic actions. Moreover, they suffer from poor energy dissipation and a sudden strength and stiffness degradation. Such an unfavorable seismic behavior obviously compromises the structural integrity of the whole system. Therefore, the experimental performance of the deficient joints has attracted considerable research interest [1-5]. Recent studies also take advantage of current development in the computer-aided nonlinear analysis which accurately reproduces the response of beam-column joints under multiaxial complex stress field [6-10]. However, further developments are still needed for improving the accuracy of the assessment procedures. To achieve this objective, refined and validated numerical models can be combined with the stochastic approach. Indeed, reproducing the nonlinear behavior of substandard joint itself in the Finite Element Method (FEM) environment is quite challenging due to a combination of different nonlinear effects (e.g., shear failure of the joint panel, slip of longitudinal reinforcements, flexure-shear interaction in the members framing into the joint). Difficulties arise even more in evolving the nonlinear FEM model to stochastic level as it requires a solution with randomized material properties.

Depending on the damage level, RC buildings with moderate to severe structural damage after the earthquakes should be demolished or repaired. However, high repair cost of drift sensitive members [11], and massive reconstruction and intrusive repair procedures [12] are among limitations of the joint repair. Moreover, assessment of threshold value for the limit joint crack and measuring the sensitivity to material properties on the joint crack are quite challenging. The current study aims at investigating the influence of material uncertainties on the global response of a substandard RC joint. The influence of each material property (i.e., input variables) on the response parameters (e.g., joint cracking, strength, and capacity and cracking at serviceability limit state) is examined by the sensitivity analysis. The threshold value for repairing the joint is obtained for the drift ratio corresponding serviceability limit state of a structure. Thus, the reparability level of the joint is investigated by monitoring the crack width corresponding to the serviceability limit state. The basic statistical characteristics (e.g., probability density function (PDF), mean, and standard deviation) of crack width the corresponding serviceability limit state are also obtained. The sensitivity of material properties on the crack width and its limit value for the given probability of exceedance are also provided as a threshold for the joint reparability.

\section{STOCHASTIC STUDY}

\subsection{Selected test program}

The refined numerical models, which were generated in ATENA Science [13] finite element method (FEM) software, are implemented to observe the progress of crack developments, its patterns, and global hysteretic response. The reliability of the proposed deterministic numerical model and its validation was recently discussed by the authors [10]. The modeling approach, the constitutive law of the materials and its parameters suitable for application to substandard beam-column joint, modeling accuracy and effectiveness in reproducing the experimental behavior, modeling advantages-disadvantages, difficulties in the modeling of substandard joints were discussed in detail in Yurdakul et al. [10]. More detailed information about the experimental response of the tested specimen (i.e. T_C3) can be found in Del Vecchio et al. [2], while the numerical response is presented in Yurdakul et al. [10]. 


\subsection{Methodology}

The randomness at material level can be simulated by computational stochastic mechanics. For this purpose, the mechanical properties of concrete and reinforcing steel were described as random variables to consider the variability in material properties. After generating the deterministic numerical model with the mean values of the material parameters listed in Table 1, the samples from the statistical analyses were the input parameters to the nonlinear FEM model. Thus, the deterministic numerical model was evolved to stochastic level. After simulating the numerical models with randomized material parameters, an uncertainty analysis was performed to identify the basic statistics of response variables (e.g., mean value, standard deviation, and PDFs corresponding to defined limit states). Then, the Spearman rank-order correlation coefficient between the randomized material parameters (input variables) and response variables was found. The input variables, which have a higher correlation coefficient, influences the global response more than the variables having a correlation coefficient close to zero [14]. The abovementioned procedure is summarized in Figure 1.

Random samples considering the random variables with the given distribution functions were generated by a stratified sampling technique named Latin Hypercube Sampling (LHS), which has an advantage of reducing the number of simulations in the sampling process, saving considerable computational time and effort [15]. The statistical correlation among prominent material parameters presented in Table 2 was defined by the optimization technique in FReET software, which is the simulated annealing method $[16,17]$. The basic statistical characteristics of the random parameters and their distribution together with correlations among them are based on experimental observations, Pukl et al. [17], fib Bulletin No.22 [18], and JCSS [19].

\begin{tabular}{|c|c|c|c|}
\hline Parameter & Mean Value, $\mu$ & $\begin{array}{c}\text { Coefficient of } \\
\text { variation }(\mathrm{COV})^{*}\end{array}$ & Distribution* \\
\hline \multicolumn{4}{|c|}{ Concrete } \\
\hline Elastic Modulus, $E_{c}(\mathrm{MPa})$ & $4700 \sqrt{ } f_{c}[20]$ & 0.10 & Lognormal (2 Parameter) \\
\hline Tensile strength, $f_{c t}(\mathrm{MPa})$ & $0.30 f_{c}^{2 / 3}[21]$ & 0.30 & Lognormal (2 Parameter) \\
\hline Compressive Strength, $f_{c}(\mathrm{MPa})$ & 16.50 & 0.15 & Lognormal (2 Parameter) \\
\hline Fracture Energy, $G_{f}(\mathrm{~N} / \mathrm{m})$ & $73 f_{c t}^{0.18}[21]$ & 0.25 & Weibull (2 Parameter) \\
\hline Compressive Strain, $\varepsilon_{c o}(\mathrm{~mm} / \mathrm{mm})$ & $f_{d} / E[22]$ & 0.15 & Lognormal (2 Parameter) \\
\hline Plastic Displacement, $w_{d}(\mathrm{~m})$ & Linear [23] & 0.10 & Lognormal (2 Parameter) \\
\hline \multicolumn{4}{|c|}{ Reinforcing Steel } \\
\hline Elastic Modulus, $E_{s}(\mathrm{GPa})$ & 196 & 0.07 & Lognormal (2 Parameter) \\
\hline Yield Strength, $f_{y}(\mathrm{MPa})$ & 470 & 0.07 & Lognormal (2 Parameter) \\
\hline Peak Strength, $f_{u}(\mathrm{MPa})$ & 600 & 0.07 & Lognormal (2 Parameter) \\
\hline Ultimate Strain, $\varepsilon_{u}(\mathrm{~mm} / \mathrm{mm})$ & 0.20 & 0.07 & Normal \\
\hline
\end{tabular}

Table 1. Material properties as random parameters and their statistical distributions 


\begin{tabular}{cccccc}
\hline \multicolumn{6}{c}{ Concrete $^{*}$} \\
\hline$E_{c}$ & 1 & 0.70 & 0.60 & 0.40 & 0.90 \\
$f_{c}$ & & 1 & 0.70 & 0.50 & 0.90 \\
$f_{c t}$ & & & 1 & 0.80 & 0.60 \\
$G_{f}$ & & $\mathrm{SYM}$ & & 1 & 0.50 \\
$\varepsilon_{c o}$ & & & & & 1 \\
\hline
\end{tabular}

\begin{tabular}{ccccc}
\hline \multicolumn{5}{c}{ Steel $^{*}$} \\
\hline & $E_{s}$ & $f_{y}$ & $f_{u}$ & $\varepsilon_{u}$ \\
$E_{s}$ & 1 & 0 & 0 & 0 \\
$f_{y}$ & & 1 & 0.75 & 0.45 \\
$f_{u}$ & & SYM & 1 & 0.60 \\
$\varepsilon_{u}$ & & & & 1 \\
\hline
\end{tabular}

* COV values, distribution functions, and correlations are based on experimental observations, Pukl et al. [17], fib Bulletin No.22 [18] and JCSS [19]

Table 2. Correlation coefficients among the random parameters

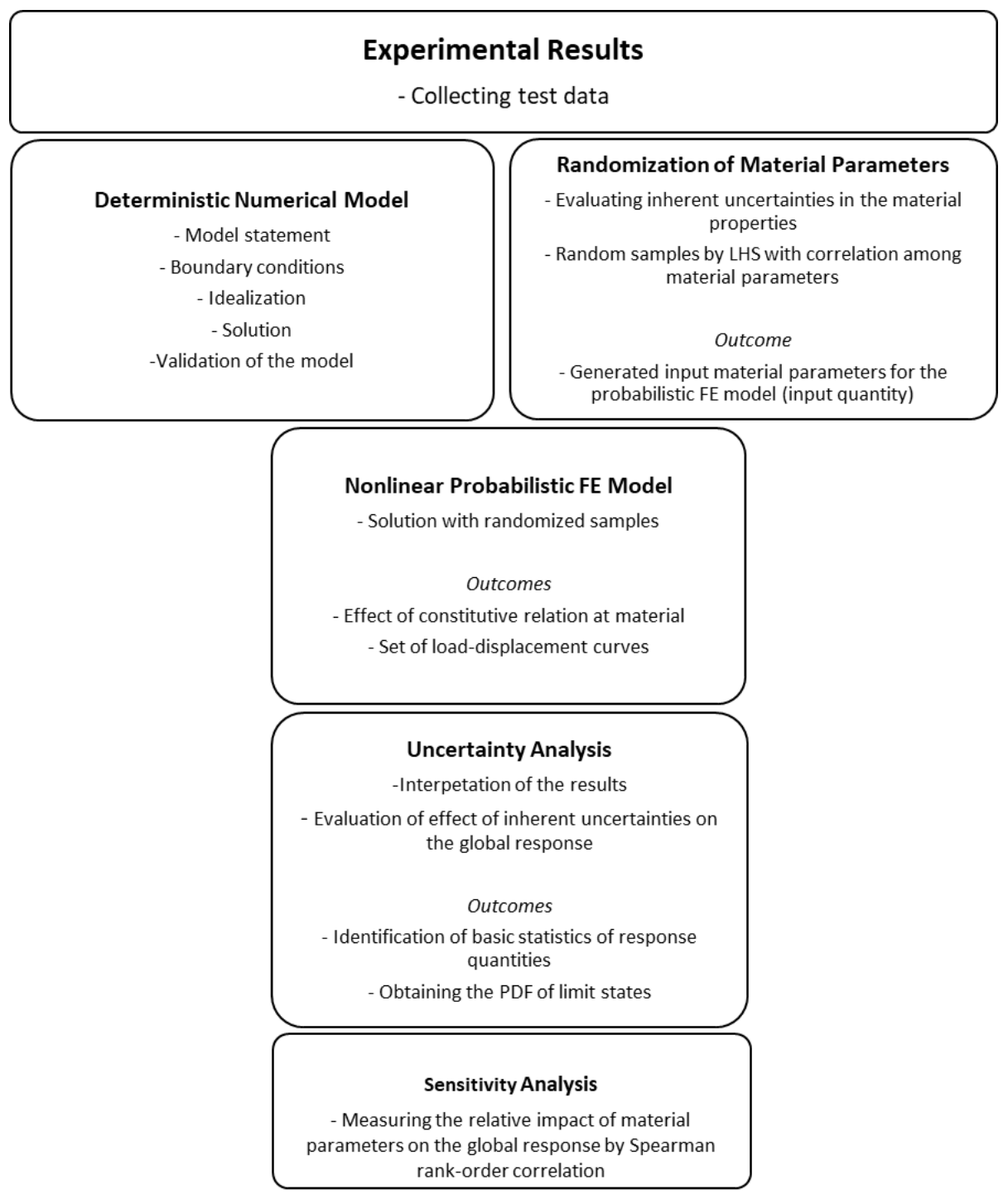

Figure 1: Flow-chart of uncertainty analysis 


\section{RESULTS AND DISCUSSION}

\subsection{Analysis of results}

The comparison with experimental results outlined that the deterministic numerical model well captures the experimental response in terms of initial stiffness and peak load [10]. The randomized parameters did not influence the initial stiffness of the specimen significantly, but remarkably affected the nonlinear response of the $\mathrm{RC}$ joint. Moreover, although the elastic modulus of the concrete and steel was randomized, the variability in the initial stiffness was relatively low. The effect of concrete strength (tensile or compressive) on the nonlinear response is more remarkable. This is mainly related to the coefficient of variation which is 0.10 for the elastic modulus of concrete, and 0.30 for the tensile strength of concrete (see Table 1). In the deterministic numerical model, the pinching effect, especially at large drift demand, does not match well with the experimental result (Figure 2a). This, of course, results in higher energy dissipation. The randomized solution could not eliminate such a major drawback of the model totally, thus the response of the models at the last imposed drift (i.e. 3\%) is not considered in this study. The other response quantities (i.e., initial stiffness, strength at different limit states, and cracking response) of the experimental results match well with the numerical response until $2 \%$ drift. Figure $2 \mathrm{a}$ and $\mathrm{b}$ show the range of load-displacement curves for the 30 (N1-N30) generated samples of joints with randomized material properties. The stochastic approach also provided the possible ranges of load-displacement curves which can be better interpreted by the envelope curves in Figure 2b.

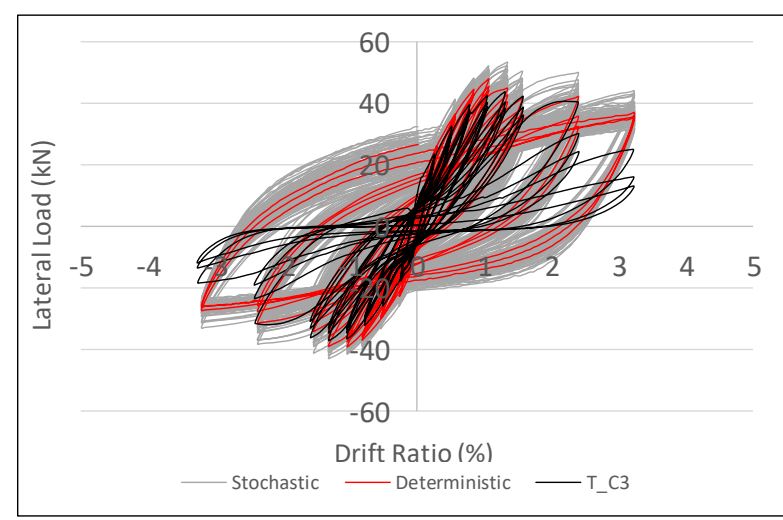

(a)

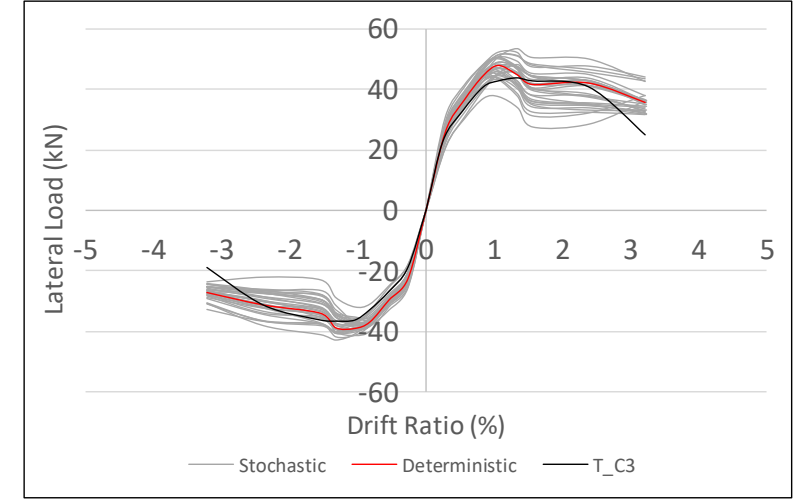

(b)

Figure 2: (a) Hysteric response (b) Envelope curve of hysteresis loops

The probability density function (PDF) corresponding the ultimate loads of peak strength together with the mean, $\mathrm{COV}$, and standard deviation, $\sigma_{r}$, was also determined from the loaddisplacement curve. In negative loading direction, $2 \sigma_{r}$-band around the mean value (i.e., prominent range of the stochastic model) covered the experimental results while it was very close to the lower boundary of $2 \sigma_{r}$-band in the positive loading direction (Table 3 ). It is worth to mention that a relatively low dispersion in the peak strength was found. This clearly shows that the randomness in the material properties has less impact on global response.

The PDF of loads and their statistical characteristics corresponding to the drift level where the inelastic response started in the numerical solutions (i.e., first joint cracking) were also calculated (Table 3). As per peak strength, a lower scatter in the global response is observed. The experimental response lies between $2 \sigma_{r}$-band. 
TEC2007 [24] defines a drift ratio of $1.00 \%$ as a serviceability limit state for a structure. This approach can be implemented at a member level as well. It is then assumed that the structural member (i.e., beam-column joint in this study) cannot be fully serviceable after reaching its serviceability limit state. Therefore, the repairability threshold value is set as a serviceability limit drift ratio. In other words, a repair solution is required when the joint reaches the drift ratio corresponding to the serviceability limit. The statistical characteristics of response variables corresponding to the serviceability limit are therefore obtained. Not only capacity but also the crack width distribution together with basic statistical characteristics corresponding to the serviceability limit state were calculated (Table 3 and Table 4). The dispersion in the capacity is rather low, on the other hand, the statistical characteristics of crack width corresponding to serviceability limit state indicated a high scatter. It clearly shows that the uncertainties in the material parameters have a high impact on cracking response than the capacity.

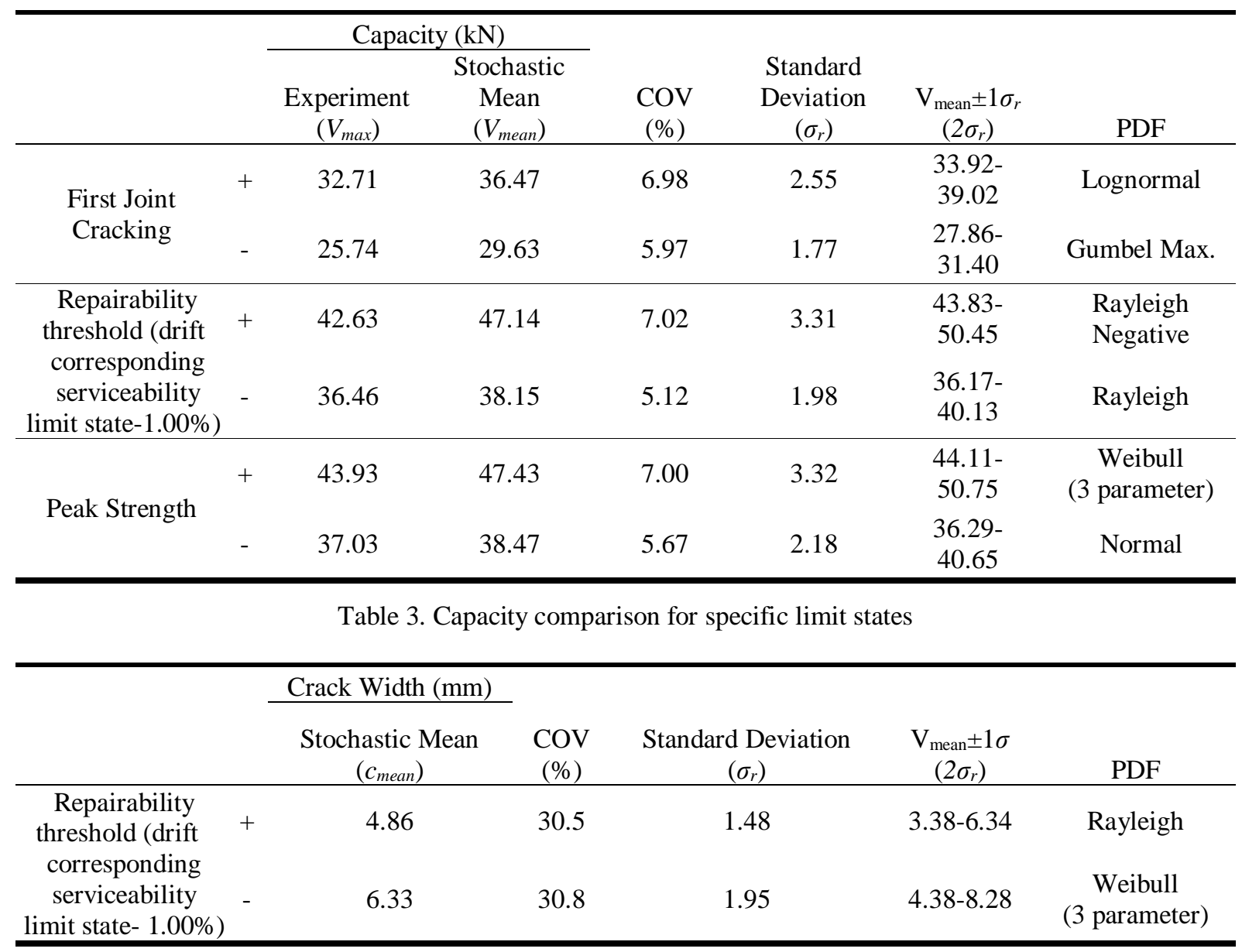

Table 4. Crack width comparison at serviceability limit state

\subsection{Sensitivity analysis}

The partial correlation coefficients (i.e., Spearman rank-order correlation) was determined between the correlation of the material properties and the stochastic capacity corresponding to each drift ratio. The contribution of concrete tensile strength $\left(f_{c t}\right)$ on the global response is the most significant as the highest correlation coefficient is calculated for the negative and positive loading direction of each cycle (Figure $3 \mathrm{a}$ and $\mathrm{b}$ ). While a medium correlation in the early stage of the loading is monitored for the concrete compressive strength $\left(f_{c}\right)$, its relative impact increased rapidly after a certain level of drift level. It can be attributed to the development of the diagonal strut mechanism perpendicular to the tension tie at the joint panel. Even though $f_{c t}$ 
plays a crucial role during the whole loading history, the compressive behavior of concrete (i.e., crushing properties) becomes critical in the subsequent drift levels. Thus, especially for large drift demands, the applied repair or retrofit strategy should consider upgrading and improving the tensile and compressive strength of concrete. The remaining material parameters have an insignificant impact on the global response in terms of lateral load capacity.

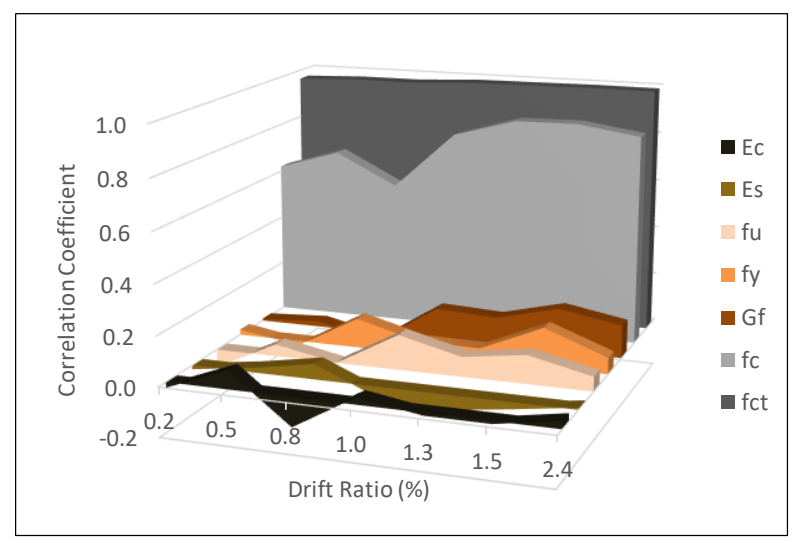

(a)

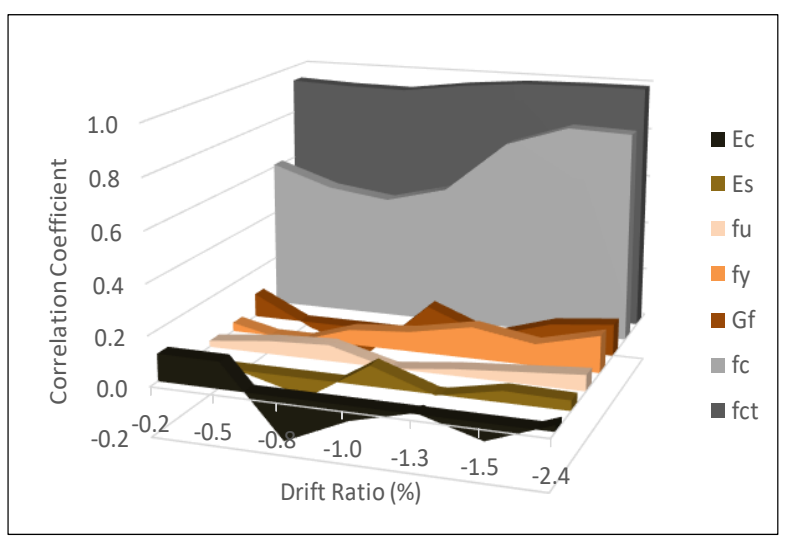

(b)

Figure 3: Sensitivity measures of the material properties on the lateral load capacity (a) Positive loading direction (b) Negative loading direction

The sensitivity of material properties on the specific response quantities used for the assessment of the joint (e.g., first joint cracking, serviceability limit state $-1.00 \%$ drift ratio- and peak strength) is also presented in Figure 4a-c. The most influential material property for the capacity corresponding to joint cracking was the tensile strength of concrete whereas a medium correlation was found for the compressive behavior. Unlike first joint cracking, the relative impact of compressive behavior becomes more recognizable for serviceability limit state and peak strength. The rest of the randomized parameters has almost no effect on the global response. Based on the above-mentioned results, the repair strategy for specific response quantities should also be developed for cracking and crushing response.

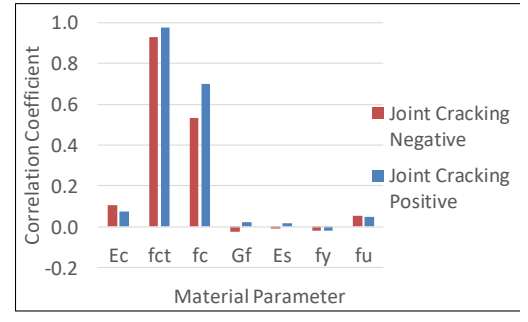

(a)

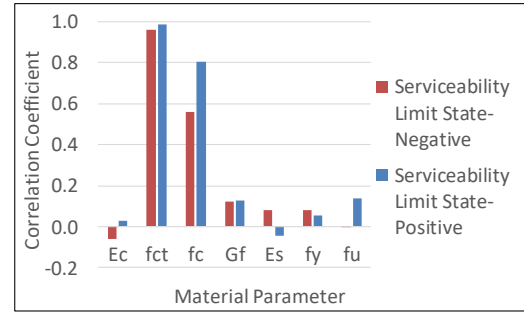

(b)

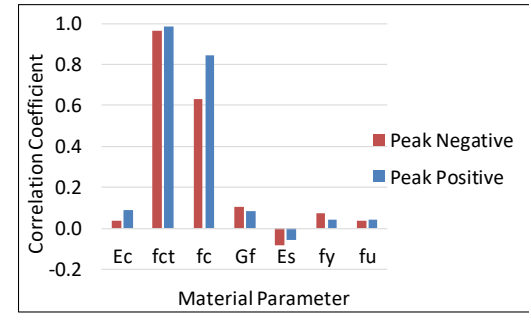

(c)

Figure 4: Sensitivity of material properties on lateral load capacity at (a) First Joint Cracking (b) Serviceability Limit State (c) Peak Strength

The drift ratios corresponding to peak loads are also sensitive to material parameters. The peak loads obtained from the stochastic analyses occur at the drift ratios varying from $0.85 \%$ to $1.35 \%$ (Figure 5). The majority of the observed peak loads concentrated at $1.00 \%$ drift ratio for both loading directions while the experimental one observed at $1.35 \%$ drift ratio. The frequency of the drift ratio of $1.35 \%$ corresponding to the peak load is rather high in the negative loading direction, whereas it was significantly low for positive drift ratios. Nevertheless, the 
experimental result is not that much different from the stochastically found ranges of drift ratios, which shows the efficiency of the model at a certain degree.

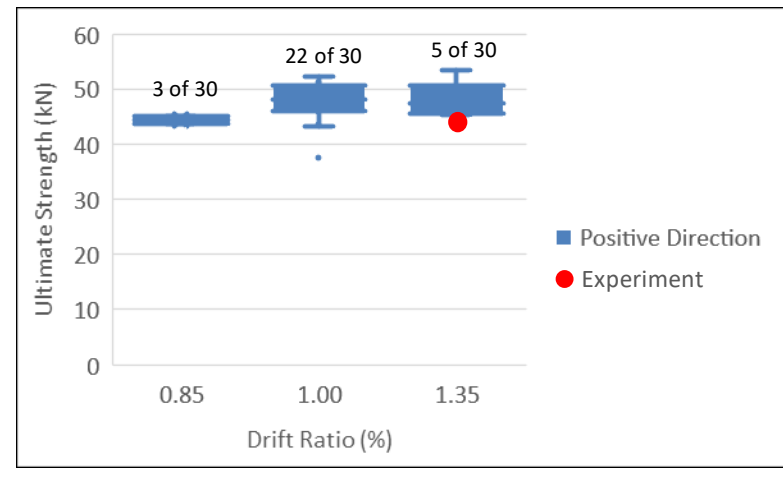

(a)

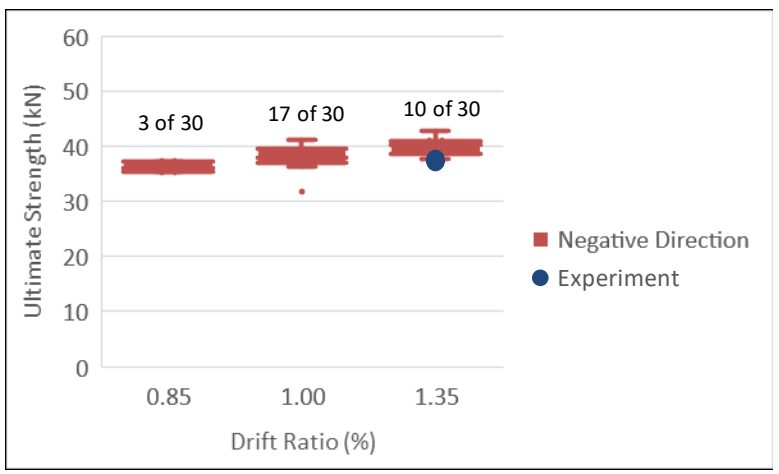

(b)

Figure 5: Distribution of drift ratio corresponding to peak strength (a) Positive loading direction (b) Negative loading direction

The attainment of serviceability limit state is assumed to occur when the deformation of the member exceeds the specified permissible deformation limit. As mentioned above, a drift ratio of $1.00 \%$ is specified for the serviceability limit of the structure by TEC2007 [24]. It is assumed that a repair solution could be required if the joint attains the corresponding drift ratio limit since it will not be serviceable beyond that limit. Therefore, the basic statistics of crack width was obtained for $1 \%$ drift level (Table 4). In cracking response, the sensitivity measures show a higher correlation on the concrete tensile strength while those related to compressive strength is in the medium range (Figure 6a).

The probability of exceedance of a certain crack width for a particular value is the area under the PDF. Figure $6 \mathrm{~b}$, which can be interpreted as a cumulative distribution function, can thus be constructed by finding the area under the PDF for a particular crack width. For the given probability, the limit crack width to take repair action can be then obtained from Figure $6 \mathrm{~b}$. A value defined in EN 1990-2002 [25] can be implemented as a limit probability of failure. EN 19902002 [25] refers to the reliability index, $\beta$, which is the inverse of the probability of failure in the Standard Normal distribution. The reliability index and corresponding failure probability $\left(p_{f}\right)$ related to irreversible serviceability limit state for the period of 50 years in RC2 type structures are 1.5 and 6.68E-02, respectively [25]. If the reliability index of $1.5\left(p_{f}=6.68 \mathrm{E}-02\right)$ was adopted, the critical crack width for exceeding that failure probability would be approximated to $2.9 \mathrm{~mm}$ and $3.5 \mathrm{~mm}$ for positive and negative loading direction, respectively. Those can be used as a limit crack width which requires repair. It should be noted that smaller value (i.e., 0.5 $\mathrm{mm}$ ) for significant joint cracking is proposed by Pantelides et al. [26]. The value of $0.5 \mathrm{~mm}$ is mostly adapted for the shear dominant joint. On the other hand, the concrete at joint back split from the surface in the simulated specimen which is mainly due to the anchorage push-out forces generated by the deformation of the beam reinforcement hooks. Unlike shear cracks, such a failure mode results in wider splitting cracks at joint back. Therefore, higher value of the proposed limit crack width for joint repair $(2.9-3.5 \mathrm{~mm})$ could be attributed to the crack formation due to anchorage push-out forces. A relatively low value of limit crack width is expected when it is evaluated for the shear cracks. Moreover, studies show that the structural members could be repairable even after excessive cracks formation at ultimate limit state [12]. On the other hand, a repair action should be taken for the structural member which is supposed to be serviceable after reaching the deformation limit of serviceability (and its corresponding crack width). This was considered a criterion of reparability in this study. 


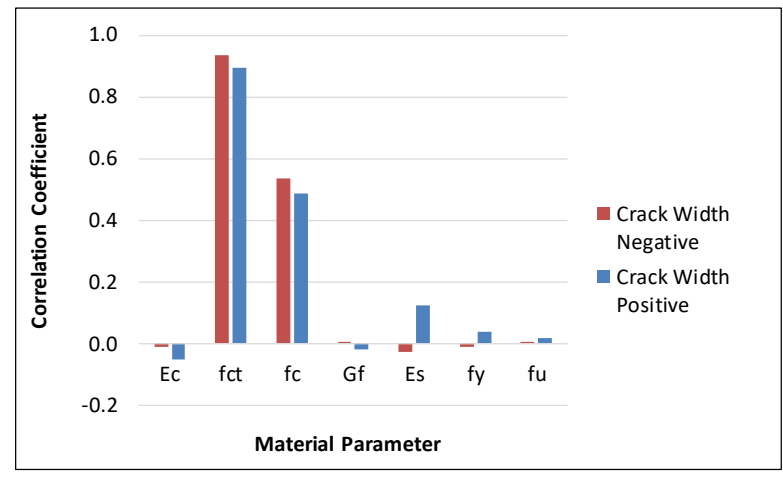

(a)

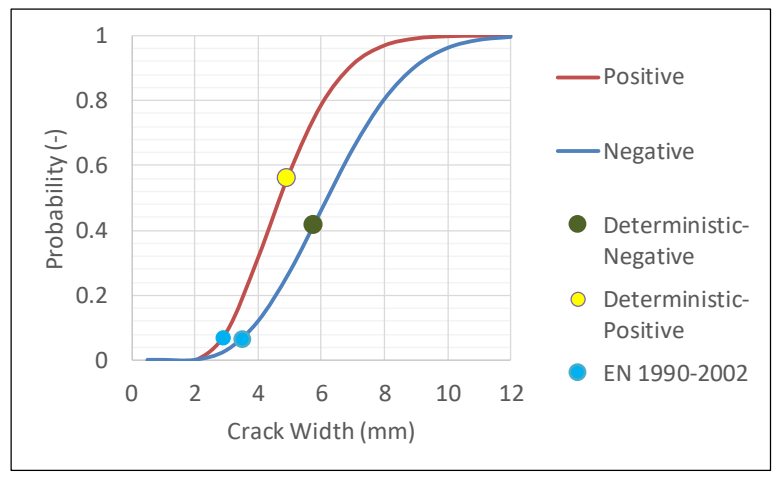

(b)

Figure 6: (a) Sensitivity measures of crack width at serviceability limit state (b) Probability of exceedance of crack width

\section{CONCLUSION}

This study investigates the response of substandard RC beam-column joints by computational stochastic mechanics. The experimentally validated deterministic numerical model was first developed and then evolved to the stochastic level to capture the randomness in the distributions of concrete material properties, and thereby characterize the capacity with possible upper and lower ranges. After the uncertainty analysis, the basic statistics of the response variables (i.e., capacity and crack width) together with the probability distribution function (PDF) were calculated for each drift level. The partial correlation coefficient between material parameters and response variables was evaluated to outline the level of significance of the contribution of each material property on the global response. The reparability level of the joint is also identified stochastically by the crack width distribution corresponding to the serviceability limit state.

The following conclusions can be drawn:

- A relatively low dispersion can be observed in the capacity corresponding to first joint cracking, serviceability limit state, and peak strength when varying between $5.67-7.02 \%$. The experimentally observed peak capacity approximately lied in $2 \sigma_{r^{-}}$ band around the mean value.

- The tensile strength of concrete displayed a crucial role in the strength and cracking response of the joint.

- Drift ratio of serviceability limit state was set as the threshold to undertake effective repair actions. The statistics of crack width corresponding to the serviceability limit state showed a high dispersion. Thus, the material properties have a high influence on cracking response. The failure probability described in EN 1990-2002 [25] for serviceability limit state approximates the limit crack width to $2.9 \mathrm{~mm}$ and $3.5 \mathrm{~mm}$ for positive and negative loading direction of the investigated substandard joint. Those were mainly due to anchorage push-out forces. Splitting cracks at joint back due to anchorage push out forces resulted in wider cracks. Therefore, proposed value of limit crack width for joint repair is higher than the one for shear cracks. 


\section{REFERENCES}

[1] W. M. Hassan, Analytical and experimental assessment of seismic vulnerability of beam-column joints without transverse reinforcement in concrete buildings. $\mathrm{PhD}$ Thesis, University of California, Berkeley, USA, 2011.

[2] C. Del Vecchio, M. Di Ludovico, A. Balsamo, A. Prota, G. Manfredi, D. Mauro, Experimental investigation of exterior RC beam-column joints retrofitted with FRP systems, Journal of Composites for Construction, 18, 04014002, 2014.

[3] Ö. Yurdakul, Ö. Avşar, Strengthening of substandard reinforced concrete beam-column joints by external post-tension rods, Engineering Structures, 107, 9-22, 2016.

[4] Ö. Yurdakul, O. Tunaboyu, Ö. Avşar, Retrofit of non-seismically designed beam-column joints by post-tensioned superelastic shape memory alloy bars, Bulletin of Earthquake Engineering, 16, 5279-5307, 2018.

[5] C. Del Vecchio, M. Di Ludovico, A. Balsamo, A. Prota, Seismic retrofit of real beam-column joints using fiber-reinforced cement composites, Journal of Structural Engineering, 144, 04018026, 2018.

[6] V. G. Haach, A. Lúcia Homce De Cresce El Debs, M. Khalil El Debs, Evaluation of the influence of the column axial load on the behavior of monotonically loaded R/C exterior beamcolumn joints through numerical simulations, Engineering Structures, 30, 965-975, 2008.

[7] S. A. Kulkarni, B. Li, W. K. Yip, Finite element analysis of precast hybrid-steel concrete connections under cyclic loading, Journal of Constructional Steel Research, 64, 190-201, 2008.

[8] C. Del Vecchio, M. Di Ludovico, A. Prota, G. Manfredi, Modelling beam-column joints and FRP strengthening in the seismic performance assessment of RC existing frames, Composite Structures, 142, 107-116, 2016.

[9] M. A. Najafgholipour, S. M. Dehghan, A. Dooshabi, A. Niroomandi, Finite element analysis of reinforced concrete beam-column connections with governing joint shear failure mode, Latin American Journal of Solids and Structures, 14, 1200-1225, 2017.

[10] Ö. Yurdakul, C. D. Vecchio, M. D. Ludovico, O. Avsar, Comparison of refined numerical modeling for substandard beam-column joints, In 16th European Conference on Earthquake Enginnering, 2018.

[11] C. Del Vecchio, M. Di Ludovico, S. Pampanin, A. Prota, Repair costs of existing RC buildings damaged by the L'Aquila earthquake and comparison with FEMA P-58 predictions, Earthquake Spectra, 34, 237-263, 2018.

[12] O. Yurdakul, O. Avsar, Structural repairing of damaged reinforced concrete beam-column assemblies with CFRPs, Structural Engineering and Mechanics, 54, 521-543, 2015.

[13] ATENA Program Documentation, Part 8., User's manuel for ATENA-GID interface, 2015.

[14] D. Novak, B. Teply, N. Shiraishi, Sensitivity Analysis of Structures, In: The fifth international conference on civil and structural engineering computing, 1993, pp. 201-207.

[15] J. Mencik, Latin hypercube sampling, Concise reliability for engineers, IntechOpen, DOI: 10.5772/62370. Available from: https://www.intechopen.com/books/concise-reliability-for-engineers/latin-hypercube-sampling, 2016.

[16] D. Novák, M. Vořechovský, R. Rusina, FReET v.1.5 - program documentation. User's and Theory Guides. http://www.freet.cz, Brno/Červenka Consulting, Czech Republic, 2015.

[17] R. Pukl, T. Sajdlova, L. Routil, D. Novák, P. Seda, Case study - Nonlinear reliability analysis of a concrete bridge., Maintenance, Monitoring, Safety, Risk and Resilience of Bridges and Bridge Networks: Proceedings of the 8th International Conference on Bridge Maintenance, Safety and Management (IABMAS2016), 2016.

[18] fib Bulletin No.22, Monitoring and safety evaluation of existing concrete structures, 2003. 
[19] Joint Committee on Structural Safety, Probabilistic model code, Part 3: Material properties, http://www.jcss.byg.dtu.dk, 2000.

[20] ACI 318M-11, Building code requirements for structural concrete and commentary (aci 318m11), USA: American Concrete Institute, 2011.

[21] CEB-FIP Model Code, Comittee Euro-International du Beton, Bulletin d'information, 2010.

[22] J. G. M. Van Mier, Multiaxial strain-softening of concrete, Part I: Fracture., Materials and Structures, RILEM, 19, 1986.

[23] B. Duran, O. Tunaboyu, Ö. Avşar, Determination of elasticity modulus of low strength concrete and its effect on the risk assessment results by DSVB, Journal of The Faculty of Engineering and Architecture of Gazi University, 32, 253-264, 2017.

[24] TEC2007, Turkish Earthquake Code, Specification for structures to be built in disaster areas. Turkey: Ministry of Public Works and Settlement Government of Republic of Turkey, 2007.

[25] EN 1990, Eurocode 0: Basis of structural design, 2002.

[26] C. P. Pantelides, J. Hansen, J. D. Nadauld, L. D. Reaveley, Assessment of reinforced concrete building exterior joints with substandard details. Technical Report PEER 2002-18, Pacific Earthquake Engineering Research Center (PEER), University of California, Berkeley, 2002. 